\title{
EFFICIENCY OF FOOTBALL TEAMS FROM AN ORGANISATION \\ MANAGEMENT PERSPECTIVE
}

\begin{abstract}
The aim of this paper is to assess the efficiency of football. Our contributions to the literature are the use of the resource-based theory and the strategy-structureperformance perspective as the study's framework, efficiency has been considered as the result of the qualities of the productive resources in football teams and efficiency is calculated in every area in the field of play. The results show that the entire team's efficiency is positively related to sporting success and the efficiency of attacking and ball recovery areas is directly related to the sport result and the efficiency of the team as a whole.
\end{abstract}

Keywords: Efficiency, Football teams, Resources, Strategy-Structure-Performance 


\section{INTRODUCTION}

The media and society in general base their assessment of football teams on their sport results and they believe that large teams are the only ones that can afford the most expensive players and that championship victory is only possible with them. There are three statements in the above sentence that require further analysis. Firstly, in Spanish First Division competitions, for example, only three results are possible: winning, remaining in the division or being relegated. This implies that teams that neither win the league nor are relegated to the second division are assessed in the same way. Secondly, the meaning of 'large team' is not clearly defined as it can refer to one with a large budget or one that belongs to a club with teams in several divisions. Lastly, believing that players earning a higher salary are the ones that achieve victory means assuming two implicit hypotheses that would have to be checked: the most expensive players play the best and their good individual playing leads to the entire team's sporting success.

Calculating an organisation's efficiency using data envelopment analysis (DEA) allows us to overcome the above-mentioned problems when assessing organisations. Firstly, it orders the organisations in the sample based on the efficiency criterion, in other words, on their use of their resources, so we can obtain a differentiated assessment of each of their performances. Secondly, as it calculates efficiency by comparing output with the volume of used resources, differences in size among the organisations in the sample are recorded and assessed in the results. Lastly, since it enables us to work with all the variables measured in physical units, the costs of the productive factors are irrelevant.

Although abundant literature measures the efficiency of football teams using DEA, no consensus exists on the approach or on the variables representing productive resources and output. This work is part of this research trend, but with three substantial differences. Firstly, it differs from previous studies in that it is premised on the resource-based theory and on the strategy-structure-performance model to justify the efficiency calculation. Secondly, efficiency is considered as a possible way to improve the sport result rather than as a performance variable in itself. Consequently, we checked for a relationship between efficiency and sporting successes and made recommendations based on our results. Lastly, the efficiency of football teams is calculated for both their performance in the field of play as a whole and for their

performance in each of the areas of play. The study sample consists of the Spanish First 
Division football teams in the 2012-2013, 2013-2014, 2014-2015, 2015-2016 and 2016-2017 seasons.

The paper is structured as follows. The theoretical framework forming the premise for the efficiency calculation is a reasoning map arising from the resource-based theory and from the strategy-structure-performance perspective; according to this reasoning map, efficiency is not considered a performance measure of organisations. This general approach is detailed in the second section and in the third it is adapted to football teams. Next, the efficiency ratios of football teams in the Spanish First Division are calculated in the study seasons. They are considered as a whole and divided by area of play to analyse the influence of efficiency on sport results. This influence is measured using correlation indices presented in the fourth section. The results are analysed and discussed in the final conclusions section.

\section{THEORETICAL FRAMEWORK FOR INTERPRETING EFFICIENCY}

Efficiency has long been used as an assessment criterion of organisations, but approaches and calculation tools have varied. Although we do not aim to present an exhaustive review of the literature in which the value of efficiency is taken as a performance indicator calculated using DEA, we can differentiate between three types of studies.

The first type comprises studies whose purpose is to assess the performance of the organisations in their sample. In these cases, efficiency is taken as a measure of performance and, consequently, these studies are limited to calculating efficiency using DEA with no recommendation for units assessed as inefficient. Examples of this approach are the studies by Fitzgerald and Storbeck (2003) and Paradi, Rouatt and Zhu (2011). Fitzgerald and Storbeck consider consumers and shareholders as different groups of individuals interested in a firm's results and they calculate efficiency in achieving their interests; Paradi, Rouatt and Zhu (2011) focus on banks and limit themselves to calculating these organisations' efficiency by differentiating between their three functions (production, brokering and profitability) and proposing only one ratio to assess their joint performance. A second group of studies also takes efficiency calculated using DEA as a performance measure, but the objective is not limited to discovering the performance of the sample organisations; instead, the authors aim to 
assess the influence certain actions have had on these organisations. Bachiller (2009), for example, evaluates the effect on efficiency caused by firm ownership changes. Lastly, a third type of studies views efficiency as a measure of performance and analyses the relationship between organisations' performance and their strategies. This group includes the work by Haugland, Myrtveit and Nygaard (2007), who analyse the effect several alternative strategies have produced on service industry results in Norway and one of the performance measures they use is efficiency. Neves and Lourenço (2009) also calculate the efficiency of a sample of hotels and use two graded as inefficient to illustrate the changes they would advise to improve their efficiency. In both papers, the recommendations were highly general and did not explore specific variables relating to the firms' internal organisation.

This lack of consensus leads to the need for a reasoning map or paradigm developed in the literature to provide a framework for the concept of efficiency and, therefore, to help us interpret our numerical results, guide our management recommendations and determine variables to represent productive resources and final products.

If interpreting efficiency intuitively equates to using productive factors, the resourcebased theory premised in Robinson (1969) springs to mind. This theory studies the relationship between organisations' internal characteristics and their performance (Wernerfelt (1984), Barney (1991), Grant (1991), Mahoney y Pandian (1992) y Helfat y Peteraf (2003)). ${ }^{1}$ The definition of resources by Barney (1991) includes all assets, capabilities, organisational processes, firm attributes, information, knowledge, and so on, and classifies them into physical, human and organisational capital resources. For this author, the resource-based theory assumes two hypotheses: organisations may be heterogeneous with respect to their productive factors and the latter are not perfectly mobile across organisations. The work by Barney (1991) stresses the influence of each organisation's own attributes on its competitive position. Furthermore, according to this author, not all resources have the potential for sustained competitive advantage for organisations, only those that meet four conditions: being valuable in the sense that they contribute to implementing strategy, being rare, inimitable and non-substitutable.

Three aspects of the resource-based theory are worth highlighting. Firstly, it emphasises organisations' internal resources. Secondly, instead of being limited to analysing the qualities of firms' productive factors, its aim is to determine their relationship with

\footnotetext{
${ }^{1}$ A recent extension of the resource-based theory is knowledge-based theory (Grant (1996)).
} 
performance. Lastly, although, according to Wernerfelt (1984), this theory aims to analyse firms from a resource viewpoint, it does not consider them isolated from their environment. Wernerfelt (1984) himself establishes that resources and products are two sides of the same coin; Barney (1991) relates sustainable competitive advantages with implemented strategy and adaptation to the environment; and Conner (1991) underscores the fact that the resource-based theory falls into strategy research as she considers it an adjustment between organisations' internal competencies and the opportunities afforded by the environment.

These three aspects remind us of the elements forming the theoretical relationship strategy-structure-performance within the strategic analysis paradigm (Ansoff (1987)). Firstly, Galunic and Eisenhardt (1994) define the structure as organisational designs, hierarchy, job descriptions, communication networks, daily tasks, formal processes, organisational culture, and so on. Pertusa-Ortega, Molina-Azorín and Claver-Cortés (2010) also analyse structure as a valuable resource and a source of competitive advantage. Lastly, the strategy-structure-performance perspective does not consider organisations as isolated from their environment. In this respect, Miles, Snow, Meyer and Coleman (1978) explicitly state that organisations plan, check and redefine how they interact with their environment and they propose a model that helps maintain coherence with the environment; Galunic and Eisenhardt (1994) remind us of the relationship between this perspective and the industrial economy's structure-conductperformance paradigm, which emphasises the relationship between environment and strategy. As the same elements appear in the strategy-structure-performance relationship and the resource-based theory, the former will also be considered in this study to propose a reasoning map as a framework for calculating and assessing organisations' efficiency.

The strategy-structure-performance paradigm maintains that when there is coherence or alignment between strategy and structure, organisations are more likely to obtain better results (Galunic and Eisenhardt (1994)). For these authors, this paradigm is the most important application of the structural contingency theory, which posits that organisations' survival and results depend on the coherence between their organisational structure and several factors, one of which might be the strategy they implement.

The relationship between the resource-based theory and the strategy-structureperformance scheme is not surprising, as the former has arisen as a reaction to the 
latter's limitations; this has resulted in studies combining both. For example, Chandler (1962), Ansoff (1965) and Hoffer and Schendel (1978), considered the first proponents of the strategic analysis paradigm, determine that strategy impacts on firm structure. Chandler (1962) explains both from a resource viewpoint: while strategy is the plan to assign resources to cope with future demand, structure is firm design to adapt existing resources to current demand. More recently, empirical studies estimating firm performance-related factors start with models linking the strategy-structure-performance perspective and the resource-based theory. Since the article by Russo and Fouts (1997) aims to verify the hypothesis that environmental performance and economic performance are positively related, it returns to the resource-based theory but explicitly states the links between the firm and its environment, as Barney (1991) does. Dai, Cantor and Montabon (2017) show how a proactive environmental strategy can influence firm performance using a strategy-structure-capabilities-performance relationship combining the two reasoning maps considered in this work.

Authors also supporting the strategy-structure-performance paradigm, such as Miles, Snow, Meyer and Coleman (1978) and Galunic and Eisenhardt (1994), highlight that research using this paradigm as a framework mostly studies organisational adaptation and adjustment between structure and strategy, although approaches differ in the importance given to the paradigm's three elements and to the direction of the influence between them.

Referring to the importance given to the paradigm's elements, the work by Galunic and Eisenhardt (1994) discusses the selection approach, which does not explore the concept of performance and whose aim is to demonstrate that only organisations with a coherent strategy and structure can survive in a competitive environment. The same authors recognise that performance can be influenced by structure attributes irrespective of the adopted strategy, and Luoma (2015) empirically studies the relationship between strategy and performance without referring explicitly to structure.

Concerning the direction of influence between strategy, structure and performance, the predominant empirical perspective has been to adopt the interaction approach (Galunic and Eisenhardt (1994)), which analyses the influence of the other two paradigm elements on performance so that strategy is considered as the independent or explanatory variable, performance as the dependent variable and structure as a mediating variable. Nevertheless, the same authors recognise that performance can 
influence structure. Pertusa-Ortega, Molina-Azorín and Claver-Cortés (2010) do not view the traditional relationship between the paradigm's elements as a given either. They assume that both strategy and structure influence performance, but they consider that the difference between the resource-based theory and the strategy-structureperformance paradigm lies in the direction of that influence between strategy and structure; in other words, strategy has a mediating effect for the resource-based theory and, in contrast, structure has a mediating effect in the strategy-structure-performance paradigm. In their work, they empirically verify whether strategy influences structure, or vice versa, to establish which of the two approaches is better supported by empirical evidence.

In this study, the resource-based theory and the strategy-structure-performance theoretical relationship will be used as the conceptual framework to calculate and study organisations' efficiency. Therefore, rather than the relationship between the strategystructure/resources-performance elements, our focal point is establishing which element efficiency identifies with.

According to Luoma (2015), performance is organisations' ultimate aim and, as a result of its importance in the literature on strategy, measuring performance has become a main area of interest. Therefore, studies focus on either proposing indicators or jointly considering all the decisions that intervene in achieving performance. The same author establishes that three approaches have been adopted to analyse the relationship between strategy and performance: the theoretical approach proposes verifying the suitability of a strategy based on its result; the empirical approach consists of analysing the impact of a certain strategy on the result using regressions in which strategy is the independent variable and performance the dependent variable; and the management approach describes how managers can improve performance.

Studies focusing on efficiency usually consider it as an objective for organisations. The first result of those studies that empirically calculate and analyse the efficiency of a real sample is the distinction between efficient and inefficient organisations and recommendations to improve the latter. Therefore, it seems that efficiency is considered on the basis of the proposal by Luoma (2015) and it can be interpreted as a performance variable.

Both the literature supporting the strategy-structure-performance perspective and the literature adhering to the resource-based theory include studies that explicitly provide 
examples of performance indicators, thus corresponding to one of the lines of research of the strategy put forward by Luoma (2015); some of these studies mention efficiency and others do not. The article by Luoma (2015) recommends using outcome indicators as well as indicators for the use of productive resources, including the calculation of efficiency, specifically using DEA and stochastic frontiers. Studies that do not mention efficiency include the work by Chandler (1962), for whom performance equates to firms' growth and survival. Also in the same group is the work by Wernerfelt (1984), who uses profitability as the performance measure in his analysis of the influence resources have on an organisation's competitive position. Lastly, Galunic and Eisenhardt (1994) propose using profitability, quality, consumer satisfaction and reputation as performance variables. They also distinguish between accountancy variables and others associated with a firm's long-term potential and they state that managers can use multiple performance measures.

Other studies, in contrast, mention efficiency, but meanings differ and they fail to explain in which of the strategic analysis elements (strategy, structure, resources and performance) it should be considered.

Studies whose framework is the strategy-structure-performance scheme usually interpret efficiency as a suitable adjustment between strategy and structure. Miles, Snow, Meyer and Coleman (1978) differentiate between effectiveness and efficiency. They assume that firms have a purpose and mechanisms to attain it; consequently, firms that assess their purposes and redefine them to adapt them to the environment are classified as effective, while efficient firms change the mechanism to attain their purpose and make the correct choice. According to Galunic and Eisenhardt (1994), efficiency is also the criterion to assess whether the adjustment between strategy and structure is appropriate. Since these authors also argue that firms that adjust well are the ones that survive in competitive markets, they add some survival or selection aspects to the term. Nevertheless, although Galunic and Eisenhardt (1994) do not include efficiency in their examples of performance variables, they assume it is one by including it in the objectives managers and strategies pursue and, in this second sense, they relate it to reducing costs and taking advantage of economies of scale.

Studies on the resource-based theory place more emphasis on this latter interpretation of efficiency related to the assessment of resource use, which is the interpretation adopted in this work. The article by Wernerfelt (1984) does not mention efficiency, but 
recognises its effects by explaining the relationship between resources and products: either the minimum quantity of resources to produce the output amount for the size chosen by the firm can be calculated, or, after choosing the firm size, the minimum quantity of resources needed for this production can be calculated. He also mentions processes classified as efficient in his resource examples. The explanation in Barney (1991) highlights the role of resources firms control, as they allow them to implement strategies that improve their efficiency and effectiveness. These terms are not defined in his work, but we can clearly deduce that he interprets efficiency as performance. However, at the end of his article he returns to the idea of efficiency related to taking advantage of productive factors by explaining that performance improves with the efficient use of resources' advantages.

We can see that there is no unanimous agreement on the concept or approach to efficiency, but if it is interpreted as good use of resources, it does not appear as a performance measure, except in the studies by Galunic and Eisenhardt (1994) and Luoma (2015).

In short, using the ideas put forward by Chandler (1962), Ansoff (1967) and Hoofer and Schendell (1978), efficiency ratios (calculated using DEA and stochastic frontiers, for example) are not considered performance indicators but variables explaining this performance. According to Chandler (1962), management's role can be seen from both a strategic and tactical perspective. Respectively, they involve allocating the organisation's resources and developing new ones for its growth in the long term, and fostering efficiency in the use of resources whose allocation has already been decided in the short term. More precisely, Pertusa-Ortega, Molina-Azorín and Claver-Cortés (2010) state that an organisation's productive resources are the source of competitive advantage in the market but have no value in themselves: consumers can observe products and their prices and, therefore, one firm differs from its competitors in the goods consumers can acquire. Final products are made from productive resources, but these refer to a firm's internal aspects that consumers cannot observe. For these authors, an organisation's performance is related to their performance in the market; therefore, performance indicators relate to income, costs, and so on, while resource indicators serve to assess the organisation's internal performance.

Organisations' use of their resources does not demonstrate the same efficiency and the reason for this evidence can be found in Barney (1991). This author's starting point is 
that firms have a heterogeneous supply of resources and he states that for a resource to generate a sustainable competitive advantage, it must be valuable, rare, inimitable and non-substitutable. Consequently, efficiency could be considered a summary value of an organisation's resources and its management of them.

On this basis, starting with the strategy-structure/resource-performance reasoning map assumed in this paper, the conclusion for locating the measurement of efficiency is as follows. Firstly, as organisations must be assessed on their performance, the most appropriate indicators have to be defined, designed or chosen (Luoma (2015)). The evaluation by Pertusa-Ortega, Molina-Azorín and Claver-Cortés (2010) is used for that purpose. It considers that these performance indicators should measure the organisation's interrelation with its market or its environment and concern products and not the use of resources. Secondly, every organisation can obtain a different level of efficiency with their productive factors. These differences may be due to the characteristics of these resources and their structure (organisational design, distribution of tasks, communication, etc.); therefore, each organisation's efficiency ratio in the use of their inputs is considered an appraisal of both their resources' characteristics and their structure.

After considering efficiency as an overall representative measure of the characteristics of resources and of the structure managing them, it can be used in empirical studies as an explanatory variable of an organisation's performance. However, if a positive relationship is detected between performance and efficiency, and given that the latter depends on the characteristics of the resources used and how they are managed, we can also analyse the variables that impact on efficiency and, based on the results, we can make recommendations on what an organisation's internal structure should be like and the type of resources it should have. 


\section{ADAPTATION OF THE PROPOSED THEORETICAL FRAMEWORK TO}

FOOTBALL

There is abundant literature in which efficiency in the use of resources by football teams is calculated using DEA. Examples are the studies by Haas (2003 a) and Haas (2003 b), Haas, Kocher and Sutter (2004), Espitia-Escuer and García-Cebrián (2004), EspitiaEscuer and García-Cebrián (2006), Espitia-Escuer and García-Cebrián (2008) and Espitia-Escuer and García-Cebrián (2010), Guzmán (2006), García-Sánchez (2007), Boscà, Liern, Martínez and Sala (2009), González-Gómez and Picazo-Tadeo (2010), Kern, Schwarzmann and Wiedenegger (2012), Papahristodoulou (2014) and Villa and Lozano (2016).

The studies noted above fall into two differentiated groups. The variables in one of them are profit components, since expenses represent inputs and income represents outputs. For example, Guzmán (2006) uses turnover as the output and Haas (2003 a and b), Haas, Kocher and Sutter (2004) and Kern, Schwarzmann and Wiedenegger (2012) use variables representing sport results together with another combination of variables, which, depending on the study, include attendance, income or stadium usage rate. As for the variables the aforementioned studies consider to represent consumed resources, Guzmán (2006) uses staff costs and overheads, Haas (2003 b) and Haas, Kocher and Sutter (2004) use salaries, Haas (2003 a) adds the population of the city where the team plays to salaries, and Kern, Schwarzmann and Wiedenegger (2012) use salaries, expenses caused by player transfers and the team's market value. The work by González-Gómez and Picazo-Tadeo (2010) only uses variables related to sporting success to represent output, but they consider the number of players available in the season and variables related to the team's financial capacity as inputs.

The second group of studies assesses the efficiency of the football teams in relation to their performance during matches. In this case, the output variables are related to sporting success and input variables are moves on the field during matches. The two major groups of moves in football are attack and defence. On this point, alternatives can be found in the literature. García-Sánchez (2007) and Boscà, Liern, Martínez and Sala (2009) estimate the efficiency of two separate processes: attack and defence. Output in the former is the number of goals and attacking moves are inputs, while in the latter, output is the inverse of the number of goals conceded and the inputs are defensive moves. Villa and Lozano (2016) include both defensive and attacking moves and the 
team's value in the inputs the teams need to score goals. However, Espitia-Escuer and García-Cebrián (2004, 2006, 2008 and 2010) do not consider defensive moves as input. On studying the efficiency of individual players, Papahristodoulou (2014) considers played minutes and a value index as an input variable.

The above-mentioned studies also differ in the purpose of the calculation of football teams' efficiency. The studies by Haas, Kocher and Sutter (2004), Espitia-Escuer and García-Cebrián (2004, 2006 and 2010), García-Sánchez (2007), Boscà, Liern, Martínez and Sala (2009) and González-Gómez and Picazo-Tadeo (2010) relate efficiency with sport results. In contrast, the studies by Guzmán (2006), Espitia-Escuer and GarcíaCebrián (2008) and Villa and Lozano (2016) seek variables to explain the efficiency ratios they obtain. Lastly, Haas (2003 a and b), Kern, Schwarzmann and Wiedenegger (2012) and Papahristodoulou (2014) only calculate efficiency ratios.

This lack of consensus on football teams' input and output variables to calculate their efficiency ratios makes it hard to propose useful recommendations to manage them. In this study, we provide a reasoning map that uses efficiency as a variable for assessing a firm's resources and we consider that applying it to football teams fills a gap in the literature on sport organisation management.

Consequently, first we determine which performance variable is relevant for this type of organisation; Késenne (2006) points out that a part of the literature argues that European professional football clubs try to maximise a utility function comprising several variables, which, besides profit, include match success, match attendance and league health. Késenne (2006) supports this second trend in his work and suggests that football clubs' objective function is to maximise their win percentage while restricting zero profit. García-del-Barrio and Szymanski (2009) also conclude that European football clubs are generally defined as sporting success maximising organizations subject to budgetary constraints. Therefore, our study will take sport results as a measurement of their performance as this is a variable that measures the teams' interrelation with their environment, manifest in their sporting rivals.

The reasoning to determine the equivalent of strategy and structure for football teams is based on the resources they have. This is the viewpoint Chandler (1962) adopts to explain both. The resources to consider in football teams are those that lead to sport results as these are used as a performance variable in the sector. An organisation's 
resources are usually work and capital, which, respectively, are players and the technical team and the club's facilities in the case of football teams.

Given the peculiarities of football teams, the player hiring process is worth examining. ${ }^{2}$ Football clubs form their staff before each season begins and they remain until it ends, with the exception of coach changes due to bad results or signings of players that some leagues allow after the start of the season. Therefore, staff can be considered the club's long-term resources. If, as we have said, a football team's objective is sport results, at the beginning of every season clubs try to hire resources with the characteristics that, in principle, will best enable them to play against their sporting rivals in the competitions they will participate in that season. Although the number of players is limited and similar among teams in the same championship, a football team's human resources (players and coaches) are highly heterogeneous since the skills they have differ.

In short, if, according to Chandler (1962), the strategy allocates resources based on future demand, the hiring for the entire season of coaches and players with experience, knowledge, skill and physical condition, for the purpose of making the club competitive in the long term, will be considered as the manifestation of the team's strategy. Furthermore, as a result of this strategy, football teams will have the resources to perform their activity. Heterogeneity in human resources observed among football teams can be described using the terms of Barney (1991): for example some teams have obtained valuable resources that take advantage of opportunities and neutralise threats in their environment (they are capable of winning matches against rival teams) and they are also rare resources that are difficult to imitate and cannot be replaced (the number of players or coaches with the best qualities is far smaller than the number of teams that would hire them and these qualities are hard to transfer to other individuals). Therefore, the resources football teams have can be a source of sustainable competitive advantages (Barney (1991)). The resource-based theory provides a highly suitable theoretical framework for a detailed analysis of the characteristics of a football team's human resources; however, if we consider that these resources are hired in anticipation of rivalry with opposing teams to obtain the sport result evidenced during matches, we avoid the problem detailed in Russo and Fouts (1997), for whom resource-based theory authors are very vague about the role linking organisations with their environment.

\footnotetext{
${ }^{2}$ As the production function of football teams is intensive in labour, this discussion ignores decisionmaking concerning physical capital.
} 
Football teams use the resources at their disposal to perform the productive process, which according to Schofield (1988), Carmichael and Thomas (1995) and Carmichael, Thomas and Ward (2000) comprises two subprocesses. The inputs of the first subprocess are the players' talent and physical condition together with the knowledge of the coaches and their technical team, and the outputs are the moves made on the field. The inputs of the second subprocess are the moves (the previous stage's product) and its output is sporting success.

In terms of the strategy-structure/resources-performance paradigm, the production function described by Schofield (1988), Carmichael and Thomas (1995) and Carmichael, Thomas and Ward (2000) would be equivalent to structure, which Chandler (1962) defines as the adaptation of existing resources to current demand. It is easy to see that the tactics developed during training and manifested during matches as moves are, actually, the short-term use of the resources the team already has.

Galunic and Eisenhardt (1994) also differentiate between the formal structure and informal interaction patterns, which, applied to a football team's productive process, would, respectively, be equivalent to each of the subprocesses established by Schofield (1988), Carmichael and Thomas (1995) and Carmichael, Thomas and Ward (2000). Team tactics are established in training sessions, and during matches, players must work together to adapt to the match conditions, their rival's moves, and so on, and apply the instructions they have received during training, although they do not have detailed instructions on what to do at each moment.

Therefore, efficiency ratios calculated for football teams assess the characteristics of their resources and of their structure. Concerning their use for club management, an analysis based on obtained efficiency values can be twofold. Firstly, checking or refuting the influence of efficiency on sporting success will suggest different club management recommendations. Secondly, we can check whether the characteristics of rarity, inimitability and the impossibility of perfect marketing that Barney (1991) puts forward as generators of competitive advantages are present in the resources hired by football teams (mainly coach and players) and whether they translate into an increase in efficiency. Even structure, represented in both the first stage of a football team's production function according to Schofield (1988), Carmichael and Thomas (1995) and 
Carmichael, Thomas and Ward (2000) and in matches, would be a variable to explain efficiency. $^{3}$

Figure 1 shows a summary of the relationship adopted in this study applied to the case of football teams.

Given that differences in efficiency can be interpreted as an effect of differences in structure and resources, this study considers moves made during matches, since they are the last part of the production function and, therefore, the consequence of these two elements of the adopted theoretical relationship. Furthermore, given that matches are played in front of spectators and a great deal of detail is known about the moves made, the productive process in football teams is not the 'black box' that Triantis (2004) and Liu, Lu, Lu and Lin (2013) describe for economic sectors in general and, therefore, efficiency values can be disaggregated with more detail. Efficiency ratios for football teams are also related to the sport results obtained to make management recommendations.

\section{EFFICIENCY AND SPORT RESULTS OF SPANISH FIRST DIVISION} FOOTBALL TEAMS

Given that the starting point in this study is that differences in the characteristics of football team resources and structure will result in efficiency differences, the efficiency ratios calculated in this section will assess the use of moves made on the field. Therefore, the input and output variables of the production function in football teams will be variables related to the game played.

From a team perspective, the time a match lasts is divided into possession and nonpossession time. In the former, teams possess the ball and have to play it to score goals. During non-possession, the rival has a chance to score a goal, so in these periods, teams try to obtain the ball again to have possibilities of scoring goals and preventing their opponent from doing so. Therefore, the output variables are goals and recovered balls. Since goals are scored as a consequence of attacking moves, total crosses, shots, assists and passes are considered input variables. Balls are recovered as a result of defensive

\footnotetext{
${ }^{3}$ This second analysis would fall into the line of research known as sport performance analysis, which consists of a detailed analysis of moves and includes observation tasks of them. This study trend includes work by Hughes and Bartlett (2002), Jones, James and Mellalieu (2004), Carling, Williams and Reilly (2007) and O’Donoghue (2010).
} 
play, so defensive actions and saves are also included as input variables. The values of the above-mentioned variables are taken for the entire season.

The tool used to calculate efficiency ratios is data envelopment analysis (DEA). Measuring the performance of football teams as a whole or of their individual players is usual with effectiveness ratios of different moves, which are the percentage of moves ending in the expected result or for which they are designed out of the total moves made. Efficiency ratios obtained using DEA can also be interpreted as an assessment of a football team's actions, but unlike effectiveness ratios, there is no individual assessment and instead all the moves made to obtain all the outputs are evaluated.

The study sample in this article is Spanish First Division football teams in the 20122017 seasons. The data used was supplied by Opta Sports.

After calculating the efficiency ratios, the purpose of this work is to interpret the relationship observed between the efficiency and performance of Spanish First Division football teams, so correlation indices between these variables and the significance level will be used as an analysis tool. This can highlight a variety of situations leading to different recommendations for football team management, always bearing in mind that every organisation seeks to improve their performance, which in our case is sport results. Situations that can occur in this relationship, presented by way of hypothesis, are the following:

a.1.) More successful teams take advantage of the moves they make during matches and their only possibility of further improving their result is by making more moves on the field without decreasing their level of use; inefficient teams, in contrast, can improve their performance by improving their efficiency, in other words, by converting match moves into output: A positive correlation was observed between efficiency in the use of moves and the sport result.

a.2.) The worst classified teams appropriately convert their moves into output, so the recommendation to improve their performance is to make more moves during matches while maintaining their level of efficiency; however, the best classified teams achieve their success by performing numerous actions on the field, which increases the difference between their result and that of other teams by improving the use of their moves, or they obtain the same 
results without needing so many actions on the field: A negative correlation was observed between efficiency in the use of moves and the sport result.

a.3.) Good use of moves has no effect on sporting success. Therefore, we would have to analyse what could influence the performance of football teams to adopt management measures to improve it: No correlation was observed.

One of the trends in applying DEA has been the attempt to explain and open the 'black box', which is normally an organisation's productive process. There is abundant literature on Network DEA, which is reviewed extensively in the studies by Castelli, Pesenti and Ukovich (2010) and Kao (2014). Tofallis (1996 and 1997) also proposes profiling, in other words, utilising DEA to separately calculate efficiency in obtaining each of an organisation's outputs using only substitute resources in product production as productive resources. There are also works that calculate the efficiency of parts of an organisation separately and aggregate them to arrive at an assessment of the organisation as a whole, without configuring a DEA variant, such as the study by Paradi, Rouatt and Zhu (2011) for the banking sector. One example of this analysis trend applied to football teams is the study by Tiedemann, Francksen and LataczLohmann (2011). Their work assesses the efficiency of individual players in the German League, differentiates them based on their position in the field and considers each of them as a different technology. Although this study also adopts the view that a variety of activities occurs during a match, it differs from the work by Tiedemann, Francksen and Latacz-Lohmann (2011) in two aspects.

Firstly, it focuses on the areas where actions occur in a match rather than on individuals. Football is a team game in which individual contribution to the end result cannot be measured. Instead, players interact in each of the areas. From a technical stance, the areas are a reference that coaches consider in planning their tactics ${ }^{4}$ and they are clearly defined, whereas one player's actions do not always exclusively occur in the position he has been assigned (a forward can make defensive moves and vice versa). This study follows the proposal put forward by Raymond (2010), who differentiates four areas with the following missions for the players in them:

In the attacking area, the players (forwards) try to score goals.

\footnotetext{
${ }^{4}$ One example could be the use and analysis of moves in area 14 and their effects. The work by Foguet Camerino, Chaverri, Anguera and Jonsson (2012) also views the areas as variables to consider in detecting play patterns in football.
} 
$\checkmark$ In the midfield area, Raymond (2010) differentiates between several types of players: defensive midfielders help behind by defending the goal (they are like defenders with the difference that they can move forward); holding midfielders stop the ball from going forward when their team is being pressed by their opponent; and attacking midfielders supply the forward with balls.

$\checkmark$ The mission of the players in the defending area is to defend their goal and interrupt the progress of the rival team's forwards.

$\checkmark$ Goal area.

Secondly, Tiedemann, Francksen and Latacz-Lohmann (2011) consider that every type of player has different missions and a defender cannot be expected to score the same goals as a forward, but these authors consider the same production function for every player type. To an extent, this study maintains this idea, but applied to the areas in which the field of play is divided: if all players are capable of obtaining the same outputs, but in different combinations depending on their position on the field, all the outputs should be present in specifying production functions and the same is true for inputs. However, it can also be assumed that if production technologies in each field area differ, since they produce a different asset or the same outputs, but in different combinations, the frontiers estimated for each area have to stem from specifying different production functions.

Again, calculating how efficiently football teams use moves made in the field areas is framed within the strategy-structure/resources-performance perspective and the relationship between efficiency by area is contrasted with both efficiency for the team as a whole and with the sport result by the way of two additional hypothesis:

b.1.) Existence of significant areas for achieving the efficiency of the entire team: These are areas for which a positive correlation is found between their efficiency and the efficiency of the whole.

b.2.) Existence of significant areas for achieving sport success: These are areas where a positive correlation is observed between the efficiency of the moves made in them and the sport result.

This study uses the information provided by Opta Sports and, to calculate the efficiency of football teams by area, we have considered that this database distinguishes five areas in the field of play classified by numbers from 1 (goal and defence) to 5 (attack and 
opponent's goal). The following correspondence can be made by combining the above with the classification by Raymond (2010):

$\checkmark$ Area 1: Defenders' area

$\checkmark$ Area 2: Defensive midfielders' area

$\checkmark$ Area 3: Holding midfielders' area

$\checkmark$ Area 4: Attacking midfielders' area

$\checkmark$ Area 5: Forwards' area

Although calculating the efficiency of football teams in the field of play's areas has been justified using the literature, the test proposed by Kruskal-Wallis (1952) has been applied to check the null hypothesis of sample equality. In calculations, the number of moves taken as inputs and outputs has been considered referred to each area. The null hypothesis of sample equality was rejected due to the test results, in other words, the areas are differentiated by the type of moves made in each of them and, therefore, studying the efficiency in each area to relate it to the sport result is worthwhile. ${ }^{5}$

In league competitions, the points obtained in every match accumulate and the total number of points at the end of the season is the performance variable considered in this work. Consequently, using Pearson's correlation index, we measure whether there is a relationship between efficiency and the number of points obtained by each of the teams participating in the league competition. However, what is relevant when assessing sporting success is the classification resulting from the total number of points achieved, so Spearman's and Kendall's correlation indices will also be calculated to measure the relationship between efficiency and each team's position in the season's final table.

The original version of DEA calculates the efficiency variable as the mathematical solution of the following linear programming problem:

$$
\text { Min } \lambda_{\mathrm{i}}
$$

s.a. $\quad \mathrm{u}_{\mathrm{i}} \leq \mathrm{z}_{\mathrm{i}} \mathrm{U}$

$\lambda_{\mathrm{i}} \mathrm{x}_{\mathrm{i}} \geq \mathrm{z}_{\mathrm{i}} \mathrm{X}$

$\mathrm{Z}_{\mathrm{i}} \in \mathrm{R}_{+}^{\mathrm{k}}$

\footnotetext{
${ }^{5}$ The Kruskal-Wallis test was applied to the number of defensive actions, assists, crosses, saves, shots, recovered balls and scored goals, disaggregating by area, in all the studied seasons. In all the cases the value of the $\mathrm{H}$ statistic proposed by Kruskal and Wallis (1952) led to the rejection of the null hypothesis of sample equality with a significance level of $95 \%$.
} 
where $\lambda_{i}$ is the technical efficiency index considering an input orientation and constant performances to scale, $u_{i}$ is the vector representing the quantities of the m products produced by organisation $i, U$ is the rank matrix k.m representing the quantities of $m$ products for $\mathrm{k}$ organisations in the sample, $\mathrm{x}_{\mathrm{i}}$ are the quantities of $\mathrm{n}$ productive factors used by the organisation whose efficiency is being measured, $\mathrm{X}$ is the rank matrix k.n of the quantities of $n$ productive factors used by the companies in the sample and $z_{i}$ is an intensity parameter vector that determines combinations of factors and observed products. In the problem solution, all the efficient units have an efficiency ratio equal to the unit and if the $\lambda_{\mathrm{i}}$ value is below 1 , the studied organisation is classified as inefficient. However, in this original DEA version, all the efficient units are allocated a ratio value equal to the unit with no possibility of discriminating between them, which can distort the values of the correlation coefficients to be calculated in this study. We have opted to solve this problem by calculating efficiency using the modified DEA version proposed by Andersen and Petersen (1993), which, continuing with the assumption of input orientation and constant performances to scale, consists of solving the following linear programming problem only for efficient units:

$$
\text { Min } \lambda_{\mathrm{i}} *
$$

$$
\begin{array}{ll}
\text { s.a. } & \mathrm{u}_{\mathrm{i}} \leq \mathrm{z}_{\mathrm{i}} \mathrm{U}^{*} \\
& \lambda_{\mathrm{i}} * \mathrm{x}_{\mathrm{i}} \geq \mathrm{z}_{\mathrm{i}} \mathrm{X}^{*} \\
& \mathrm{z}_{\mathrm{i}} \in \mathrm{R}_{+}^{\mathrm{k}-1}
\end{array}
$$

where $u_{i}$ is the vector representing the quantities of the m products produced by the analysed efficient organisation $\mathrm{i}, \mathrm{U}^{*}$ is the rank matrix $(\mathrm{k}-1) \mathrm{m}$ representing the quantities of $\mathrm{m}$ products for the organisations in the considered sample from which the one analysed has been excluded, $x_{i}$ are the quantities of $n$ productive factors used by the organisation whose efficiency is being measured, $X^{*}$ is the rank matrix $(k-1) \cdot n$ of the quantities of $\mathrm{n}$ productive factors used by the units in the sample, excluding the one studied, and $z_{i}$ is an intensity parameter vector that determines combinations of factors and observed products. The efficiency ratios obtained from solving (2) are no longer limited because as the reassessed efficient unit is not included in the reference sample, the value of ratio $\lambda_{\mathrm{i}}$ is equal to or above one. Using this DEA version, the efficiency ratio values of efficient organisations differ and a higher value is interpreted as representing a higher level of efficiency. The efficiency ratio of inefficient organisations 
has not changed from the ratio obtained in the original version after applying the version by Andersen and Petersen (1993).

The first efficiency calculation in this study corresponds to the entire football team using all the above-mentioned input and output variables. To ensure the linear programming problem arising from using DEA has enough degrees of freedom, Despotis (2002) establishes that the number of variables and observations must follow this rule:

$$
\mathrm{k} \geq \max \left\{\mathrm{m}^{*} \mathrm{n}, 3(\mathrm{~m}+\mathrm{n})\right\}
$$

where $\mathrm{k}$ is the number of observations included in the sample, $\mathrm{m}$ the number of outputs and $\mathrm{n}$ the number of inputs as in (1). Applying the above to this study, the number of teams in the Spanish First Division is 20 and two output variables and six input variables have been established, therefore, $20<3 *(2+6)>6 * 2$ and the rule put forward by Despotis (2002) is not fulfilled. To solve this problem, we applied profiling (Tofallis (1996) and Tofallis (1997)), which proposes separate calculations for efficiency in obtaining assets that do not use the same resources and that only include substitute resources as inputs. By applying these ideas to a football team's game, we can calculate the efficiency of moves made during ball possession (goals as output and total crosses, shots, assists and passes as inputs) and of moves made during non-possession (recovered balls as output and defensive actions and saves as input). ${ }^{6,7}$

By observing the correlation indices calculated and presented in table 1, first, a positive and significant relationship can be gleaned between efficiency and sport results when the latter are measured as points obtained during the competition and as the final classification position. Therefore, efficiency in the use of moves in football teams positively affects performance.

Nevertheless, the values obtained show that the correlation between the sport result and efficiency in ball possession is higher than if efficiency is considered in non-possession. Except for possession efficiency in the 2016/2017 season, for all associations between efficiency and results, Pearson's correlation index is higher than Spearman's and Spearman's is higher than Kendall's.

\footnotetext{
${ }^{6}$ It is easy to establish that the rule proposed by Despotis (2002) is fulfilled in both linear programming problems set up in order to calculate efficiency for possession and non-possession.

Obtained results for efficiency ratios are showed in Annex 1.
} 
In the first three seasons studied in this research, the values of each of the correlation indices were similar, but in the 2015/2016 season several changes were observed. Firstly, there was a considerable decrease in Pearson's and Spearman's indices in the correlation between sport results and efficiency in possession moves. Secondly, Pearson's index for non-possession efficiency presented a substantial increase. This meant that the correlation of the sport result with efficiency in this season was virtually the same in possession and non-possession. In contrast, Kendall's correlation index maintained similar levels to those of previous seasons for both possession and nonpossession. For the last season studied, all the calculated correlation indices returned to values similar to those in the seasons prior to 2015/2016, except the efficiency index of possession moves with sport results, which did not return to the values of the first seasons.

Two calculations can check the possible correlation of efficiency in the areas of play with the efficiency of the team as a whole and with sport results.

The first considers that the same types of moves can be made in all the areas, so each one's efficiency is calculated taking all the variables of a football team's activity as inputs and outputs. In the case studied in this paper, we again find an insufficient number of degrees of freedom since the number of examined variables and observations is again eight and 20 , respectively. ${ }^{8}$

\footnotetext{
${ }^{8}$ Given that the input and output variables in the calculations would be the same for all the areas, the efficiency ratios can be calculated again but this time using a non-parametric metafrontier approach. This tool was proposed by Battese and Rao (2002), Battese, Rao and O’Donnell (2004) and O’Donnell, Rao and Battese (2008). These authors consider that there are units in the study sample that use different technologies and they calculate the efficiency of all of them using a joint frontier (or metafrontier) approach. Consequently, the efficiency of every organisation studied can be calculated taking organisations using the same technology as a reference and also using the same joint sample in order to recommend the technology that would enable them to use their resources efficiently. Although the term metafrontier was not mentioned, the work by Charnes, Cooper and Rhodes (1981) uses this methodology. Applied to football, Tiedemann, Francksen and Latacz-Lohmann (2011) propose a variant of the original metafrontier to make feasible recommendations to organisations classified as inefficient. More recent studies on the metafrontier approach are by Afsharian (2017) and Tsekouras, Chatzistamoulou and Kounetas (2017). In this study, the metafrontier calculation of efficiency consists of taking the areas of play of 20 football teams competing in the Spanish First Division as units, thus solving the degrees of freedom problem since the number of observations suffices for processing with eight input and output variables. Efficiency was calculated in the areas into which the football teams' game is divided using the
} 
A second calculation of efficiency by area assesses the use teams make of resources to transform them into the moves for which each area of play is designed. For these calculations, the variables used to represent resources and products are shown in table 2 and their values are the ones they have in each of the areas.

Firstly, with this proposal, the problem of the number of degrees of freedom when obtaining efficiency ratios with DEA vanishes, since the rule of Despotis (2002) is fulfilled in the areas with more input and output variables: $20>3 *(2+1)>2 * 1$. Therefore, we calculate the efficiency of the moves for which every area has been designed in this study. After discovering the efficiency ratios, their correlation with the sport results is measured to check whether they are influenced by the efficiency of every one of the parts into which the production function of football teams has been divided. As in the case of the correlation between the joint efficiency of the teams and their sport results, Pearson's correlation index is calculated alongside Spearman's and Kendall's, since competition success can be evaluated using both the points obtained at the end of the season and the final position in the league table. Also checked is whether there is a relationship between playing efficiency in each of the areas and the team's overall efficiency, which in this study has been divided into possession efficiency and nonpossession efficiency. Only Pearson's correlation index is calculated for this purpose since, in this case, the relationship between efficiency orders is not relevant. Table 3 shows the results we obtained.

metafrontier approach and hardly any changes were observed in the efficiency ratio values calculated for each of the areas individually, so they are not presented here. Nevertheless, we believe it is important to refer to them because they show that how the game is played differs in each area, as shown by the Kruskal-Wallis test results, and that the type of play that is the best technology to use in each area is the type already used. 
The efficiency of the actions in area 3 is positively and significantly correlated with the sport results and with possession and non-possession efficiency. Virtually the same result was observed for efficiency in area 2 (except in the correlation with sport results in the 2013/2014 season, which only present correlation with the points, but not with the league table order) and in area 5 (no correlation was observed with non-possession efficiency in the 2015/2016 season). We could conclude, therefore, that the efficiency of moves in these areas contributes to sport results both directly and indirectly through improved possession and non-possession efficiency, which, as gleaned from the results in table 1, are positively correlated with sport results.

The fact that there is no correlation between efficiency in area 1 and possession efficiency or between efficiency in area 4 and non-possession efficiency in any of the seasons analysed in this study is worth highlighting. This result indicates specialisation in the type of moves made in these areas: good use of the moves in area 1 only has a positive influence on non-possession efficiency and the same occurs for the moves in area 4 and possession efficiency.

Finally, efficiency in the moves in area 1 has no influence on the results, while efficiency in area 4 is positively correlated with the points obtained in all the seasons except the 2012/2013 season and with the classification in the league table in the 2013/2014 and 2014/2015 seasons.

\section{CONCLUSIONS}

This study aims to fill a gap in the sports economics literature by examining the role of the calculation of efficiency in the management of organisations in general and its particular application to football teams. The approach has resulted from combining the resource-based theory with the strategy-structure-performance perspective. Football teams are labour-intensive and players and coaches can be considered as strategic resources because they are not easily imitable nor easily substitutable. Furthermore, due to strategy planning, football teams form their staff at the beginning of the season and, as a result of their training sessions, they adapt their resources to the sport rivalry situation in every match, supplemented by the informal communication that occurs during it. Training sessions and adaptations during matches are considered, respectively, as the formal and informal structure of football teams. Clubs' performance has been 
measured by their sport results obtained from the moves they make during matches combined with their rivals' moves: while teams are in possession of the ball, they try to score goals with attacking moves, and during non-possession time, their play is defensive to prevent their opponents from scoring and to regain possession of the ball. The sport result of every match depends on goal difference and it accumulates in the form of points to arrive at a final result for the season.

Efficiency, which measures an organisation's use of resources to obtain its output, has not been considered in this study as a measure of performance, but rather as an overall assessment of the characteristics of the club's essentially human resources, since heterogeneity in player and coach characteristics leads to differences in the use of moves made on the field to obtain the outputs of goals and recovered balls. This study's contribution is proposing that the correlation between efficiency and sport results (performance) guides both the characteristics of the resources that should be hired to configure strategy, and activities to perform during training sessions and matches (structure).

The study sample was formed by the Spanish First Division football teams in the seasons between 2012 and 2017. The tool used to calculate their efficiency was DEA and data availability enabled us to calculate ratios for teams as a whole (although possession and non-possession efficiency was calculated due to a degrees of freedom problem) and in areas of play. The correlation observed between efficiency and sport results and between efficiency as a whole and by area has led us to establish the conclusions presented below.

Firstly, possession efficiency and non-possession efficiency are positively correlated with sport results, whether they are measured in points obtained during the season or in the final position in the league table. Therefore, good use of moves fosters sport results and, consequently, inefficient teams can improve their sport results not only by making more moves but also by making better use of them. Referring to the reasoning map detailed in this study, we recommend football teams hire players and coaches with characteristics that foster good use of moves and that this idea guides tactics established during training sessions. This recommendation is very general and we have opened the 'black box' that represents organisations and assess the efficiency of their parts.

Given that disaggregated information is available on the moves of the teams in the sample, efficiency ratios were calculated using DEA for the areas the game of play has 
been divided into. Taking as a basis the results presented in this study, those obtained for areas 2, 3 and 5 should be differentiated from those obtained for areas 1 and 4 . Efficiency in the use of moves observed in the first group is positively correlated with the efficiency of the team as a whole in possession and non-possession and with sport results. Therefore, from the point of view of resources, strategy and structure, the recommendation for football teams should be to hire players and train them with the purpose of not wasting any chances to convert defensive actions into recovered balls or to transform crosses and shots into goals. Not only would this have a positive direct effect on sport results, it would also increase possession and non-possession efficiency, thus improving sport results through an indirect effect. The results for area 5 (over $90 \%$ correlation between its efficiency and possession efficiency) are extremely relevant as they show the importance of an attacking game that does not waste opportunities to convert actions into goals, since possession efficiency is highly related to sport results and one way of attaining this efficiency is through efficiency in the moves made in area 5. In other words, good use of moves in this area by hiring players with suitable qualities for it and appropriate training to optimise these qualities enhance sport results since, besides the direct relationship between efficiency and success, an indirect relationship between both was detected through possession efficiency, which could be attributed a moderating effect on sports achievements.

Efficiency in the use of moves made in areas 1 and 4, in contrast, bears hardly any relationship with sport results. Except in one of the analysed seasons, efficiency obtained in area 4 is positively correlated with points obtained, its relationship with non-possession efficiency can be considered null and in the two seasons in which there is a positive relationship with possession efficiency, there is also a positive relationship with measured results and position in the final league table. Obviously, the availability of players that do not perform defensive actions or excessive passes for assists would benefit sport results, but this lacks any major relevance. The results obtained for area 1 show that when hiring players and practising tactics in training sessions, emphasis must be placed on ball recovery by means of defensive actions in that area and the goalkeeper's saves, and that the number of these types of moves does not matter since performing fewer of them has virtually no effect on sport results. One reason for this lack of relationship between efficiency in area 1 and sport results is considering the goalkeeper's saves as an input of its productive process. Firstly, the number of saves is 
related to the opponent's shots at goal; therefore, the team does not have total power of decision over this type of move. Secondly, the best sport result outcome is for there to be as many saves as opponent's shots, so fewer moves of this type are not advisable.

In short, the results obtained in this study seem to demonstrate that the availability of players and coaches that achieve efficiency in moves is beneficial from a sport result standpoint in areas where there is some specialisation in the tasks performed (areas 2 and 3 to recover balls and 5 to score goals). In contrast, in areas where moves are more transitional (balls are recovered in area 1, but the opponent's goals must also be avoided, and assists towards area 5 are made in area 4), it seems that players should be hired and trained to perform a high quantity of output moves, although they must make many input moves for that purpose.

We can also glean from the results that efficiency related to sport results is either efficiency that leads to ball possession (efficiency in areas 3 and 4 means the ball is recovered with few defensive actions, in other words, the opponent's possession time is shortened) or efficiency that leads to scoring goals once in possession of the ball (efficiency in area 5 is interpreted as obtaining goals with hardly any use of the cross and shot inputs).

To conclude, this paper's contribution consists of using business management and strategic analysis theories (resource-based theory and strategy-structure-performance framework) and considering efficiency as a measure of a football team's use of moves on the field and not as a performance variable. In short, efficiency has been interpreted as a consequence of strategic characteristics (contributing value, no substitutes, impossibility of imitating) of sports clubs' resources (essentially human). This means that despite considering the moves made during matches as input variables in the calculations, the recommendations made refer to human resources, which are, together with the capital, the basic productive resources established in economic theory.

Despite calculating the efficiency of football teams by area and not just for each of them as a whole, this study obviously does not detail the physical characteristics that every club should seek in the players it hires or the activities it should perform during training sessions to enhance these qualities. However, this could be a first step towards useful proposals for a team's approaches to sport activity by integrating lines of research based on management and sport performance analysis, since the latter provides information on move techniques, training types, and so on. 


\section{REFERENCES}

Afsharian, M. (2017). Metafrontier efficiency analysis with convex and non-convex metatechnologies by stochastic nonparametir envelopent of data. Economics Letters, 160, 1-3.

Andersen, P., \& Petersen, N. C. (1993). A Procedure for Ranking Efficient Units in Data Envelopment Analysis. Management Science, 39(10), 1261-1264.

Ansoff, I. (1965). Corporate Strategy. McGraw Hill Inc.

Ansoff, I. (1987). The emerging paradigm of strategic benavior. Strategic Management Journal, 8(6), 501-515.

Bachiller, P. (2009). Effect of ownership on efficiency in Spanish companies. Management Decision, 47(2), 289-307.

Barney, J. (1991). Firm Resources and Sustained Competitive Advantage. Journal of Management, 17(1), 99-120.

Battese, G., \& Rao, D. (2002). Technology Gap, Efficiency, and Stochastic Metafrontier Function. International Journal of Business and Economics, 1(2), 87-93.

Battese, G., Rao, D., \& O'Donnell, C. (2004). A Metafrontier Production Function for Estimation of Technical Efficiencies and Technology Gaps for Firms Operating Under Different Technologies. Journal of Productivity Analysis, 21(1), 91-103.

Boscà, J., Liern, V., Martínez, A., \& Sala, R. (2009). Increasing offensive and defensive efficiency? An analysis of Italian and Spanish football. Omega, 37(1), 63-78.

Carling, C., Williams , A., \& Reilly, T. (2007). Handbook of Soccer Match Analysis. New York: Routledge.

Carmichael, F., \& Thomas, D. (1995). Production and efficiency in team sports: an investigation of rugby league football. Applied Economics, 27(9), 859-869.

Carmichael, F., Thomas, D., \& Ward, R. (2000). Team Performance: The Case of English Premiership Football. Managerial and Decision Economics, 21(1), 3145.

Castelli, L., Pesenti, R., \& Ukovich, W. (2010). A classification of DEA models when the internal structure of the Decision Making Units is considered. Annals of Operations Research, 173(1), 207-235.

Chandler, A. D. (1962). Stragegy and Structure. Chapters in the History of the Industrial Enterprise. Cambridge, Massachussetts: The MIT Press. 
Charnes, A., Cooper, W., \& Rhodes, E. (1981). Evaluating Program and Managerial Efficiency: An Application of Data Envelopment Analysis to Program Follow Through. Management Science, 27(6), 668-697.

Conner, K. R. (1991). A Historical Comparison of Resource-Based Theory and Five Schools of Thought Within Industrial Organization Economics: Do We Have a New Theory of the Firm? Journal of Management, 17(1), 121-154.

Dai, J., Cantor, D. E., \& Montabon, F. L. (2017). Examining corporate environmental proactivity and operational performance: A strategy-structure-capabilitiesperformance perspective within a green context. International Journal of Production Economics, 193, 272-280.

Despotis, D. (2002). Improving the discriminating power of DEA: focus on globally efficient units. Journal of the Operational Research Society, 53(3), 314-323.

Espitia-Escuer, M., \& García-Cebrián, L. (2004). Measuring the Efficiency of Spanish First-Division Soccer Teams. Journal of Sports Economics, 5(4), 329-346.

Espitia-Escuer, M., \& García-Cebrián, L. (2006). Performance in sports teams: results and potential in the professional soccer league in Spain. Management Decision, 44(8), 1020-1030.

Espitia-Escuer, M., \& García-Cebrián, L. (2008). Measuring the Productivity of Spanish First Division Soccer Teams. European Sport Management Quarterly, 8(3), 229-246.

Espitia-Escuer, M., \& García-Cebrián, L. (2010). Measurement of the efficiency of football teams in the Champions League. Mangerial and Decision Economics, 31, 373-386.

Fitzgerald, L., \& Storbeck, J. (2003). Pluralistic views of performance. Management Decision, 41(8), 741-750.

Foguet Camerino, O., Chaverri, J., Anguera, M., \& Jonsson, G. (2012). Dynamics of the game in soccer: Detection of T-patterns. European Journal of Sport Science, 12(3), 216-224.

Galunic, D., \& Eisenhardt, K. M. (1994). Renewing the Strategy-Structure-Performance Paradigm. Research on Organizational Behavior, 16, 215-255.

García-del-Barrio, P., \& Szymanski, S. (2009). Goal! Profit Maximization Versus Win Maximization in Soccer. Review of Industrial Organization, 34(1), 45-68.

García-Sánchez, I. M. (2007). Efficiency and effectiveness of Spanish football temas: A three-stage-DEA approach. Central European Journal of Operations Research, 15(1), 21-45. 
González-Gómez, F., \& Picazo-Tadeo, A. (2010). Can We Be Satisfied With Our Football Team? Evidence From Spanish Professional Football. Journal of Sports Economics, 11(4), 418-422.

Grant, R. (1996). Towards a knowledge-based view of the firm. Strategic Management Journal, 17(S2), 109-122.

Grant, R. M. (1991). A resource-based perspetive of competitive advantage. California Management Review, 33(3), 114-135.

Guzmán, I. (2006). Measuring Efficiency and Sustainable Growth in Spanish Football Teams. European Sport Management Quarterly, 6(3), 267-287.

Haas, D. J. (2003 a). Productive Efficiency of English Football Teams. A Data Envelopment Analysis Approach. Managerial and Decision Economics, 24(5), 403-410.

Haas, D. J. (2003 b). Technical Efficiency in the Major League Soccer. Journal of Sports Economics, 4(3), 203-2015.

Haas, D., Kocher, M. G., \& Sutter, M. (2004). Measuring Efficiency of German Football Teams by Data Envelopment Analysis. Central European Journal of Operations Research, 12(3), 251-268.

Haugland, S., Myrtveit, I., \& Nygaard, A. (2007). Market orientation and performance in the service industry: A data envelopment Analysis. Journal of Business Research, 60(11), 1191-1197.

Helfat, C., \& Peteraf, M. (2003). The dynamic resource-based view: capability lifecycles. Strategic Management Journal, 24(10), 997-1010.

Hoffer, C., \& Schendel, D. (1978). Strategy formulation: Analytical concepts. South Western.

Hughes, M. D., \& Bartlett, R. M. (2002). The use of performance indicators in performance analysis. Journal of Sports Sciences, 20(10), 739-754.

Jones, P. D., James, N., \& Mellalieu, S. D. (2004). Possession as a performance indicator in soccer. International Journal of Performance Analysis in Sport, 4(1), 98-102.

Kao, C. (2014). Network data envelopment analysis: A review. European Journal of Operational Research, 239(1), 1-16.

Kern, A., Schwarzmann, M., \& Wiedenegger, A. (2012). Measuring the efficiency of English Premier League football. Sport, Business and Management: An International Journal, 2(3), 177-195. 
Késenne, S. (2006). The Win Maximization Model Reconsidered Flexible Talent Supply and Efficiency Wages. Journal of Sports Economics, 7(4), 416-427.

Kruskal, W., \& Wallis, W. (1952). Use of Ranks in One-Criterion Variance Analysis. Journal of the American Statistical Association, 47(260), 583-621.

Liu, J. S., Lu, L. Y., Lu, W.-M., \& Lin, B. J. (2013). Data envelopment analysis 19782010: A citation-based literature survey. Omega, 41(1), 3-15.

Luoma, M. A. (2015). Revisiting the strategy-performance linkage. An application of an empirically derived typology of strategy content areas. Management Decision, 53(5), 1083-1106.

Mahoney, J., \& Pandian, J. (1992). The resource-based view within the conversation of strategic management. 13(5), 363-380.

Miles, R. E., Snow, C. C., Meyer, A. D., \& Coleman, H. J. (1978). Organizational Strategy, Structure, and Process. The Academy of Management Review, 3(3), 546-562.

Neves, J., \& Lourenço, S. (2009). Using data envelopment analysis to select strategies that improve the performance of hotel companies. International Journal of Contemporary Hospitality Management, 21(6), 698-712.

O'Donnell, C., Rao, D., \& Battese, G. (2008). Metafrontier frameworks for the study or firm-level efficiencies and technoloy ratios. Empirical Economics, 34(2), 231255.

O'Donoghue, P. (2010). Research Methods for Sports Performance Analysis. New York: Routledge.

Papahristodoulou, C. (2014). Evaluating the Performance of UEFA Champions League Scorers. International Journal of Sports Science, 4(6A), 1-11.

Paradi, J., Rouatt, S., \& Zhu, H. (2011). Two-stage evaluation of bank branch efficiency using data envelopment analysis. Omega, 39(1), 99-109.

Pertusa-Ortega, E. M., Molina-Azorín, J., \& Claver-Cortés, E. (2010). Competitive strategy, structure and firm performance. A comparison of the resource-based view and the contengency approach. Management Decision, 48(8), 1282-1303.

Raymond, M. (2010). Soccer Field Diagram. The 4 Zones of the Field. Ezine @ rticles.

Robinson, J. (1969). The economics of imperfect competition. UK: Palgrave MacMillan.

Russo, M. V., \& Fouts, P. A. (1997). A Resource-Based Perspective on Corporate Environmental Performance and Profitability. Academy of Management Journal, 40(3), 534-559. 
Schofield, J. (1988). Production functions in the sports industry: an empirical analysis of professional cricket. Applied Economics, 20(2), 177-193.

Tiedemann, T., Francksen, T., \& Latacz-Lohmann, U. (2011). Assessing the performance of German Bundesliga football players: a non-parametric metafrontier approach. Central European Journal of Operations Research, 19(4), 571-587.

Tofallis, C. (1996). Improving Discernment in DEA Using Profiling. Omega, 24(3), 361-364.

Tofallis, C. (1997). Input Efficiency Profiling: An Application to Airlines. Computers \& Operations Research, 24(3), 253-258.

Triantis, K. P. (2004). Engineering applications of Data Envelopment Analysis. In W. W. Cooper, L. M. Seiford, \& J. Zhu (Eds.), Handbook on Data Envelopment Analysis (pp. 401-441). Boston/Dordrecht/London: Kluwer Academic Publishers.

Tsekouras, K., Chatzistamoulou, N., \& Kounetas, K. (2017). Productive performance, technology heterogeneity and hierachies: Who to compare to whom. International Journal of Production Economics, 193, 465-478.

Villa, G., \& Lozano, S. (2016). Assessing the scoring efficiency of a football match. European Journal of Operational Research, 255(2), 559-569.

Wernerfelt, B. (1984). A Resource-based View of the Firm. Strategic Management Journal, 5(2), 171-180.

Table Legends:

Figure 1. Strategy-Structure/Resources-Performance Relationship applied to football teams.

Table 1. Correlation indices between efficiency and sport results.

Table 2. Input and output variables in every area of play. 
Table 3. Correlation indexes between efficiency by areas, joint efficiency of teams and sport results.

Annex 1. Efficiency ratios for Spanish First Division football teams. 